Post-print version of:

Publisher: SAGE

Journal paper: Proceedings of the Institution of Mechanical Engineers, Part M. Journal of Engineering for the Maritime Environment, 232(2): 234-244.

Title: Optical Measurements and Experimental Investigations in Repeated low Energy Impacts in Powerboat Sandwich Composites

Authors: F. Cucinotta, A. Paoli, G. Risitano, F. Sfravara

Creative Commons Attribution Non-Commercial No Derivatives License

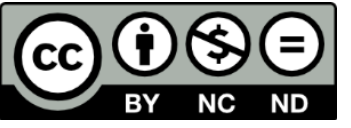

DOI Link: https://doi.org/10.1177/1475090217720619 


\title{
Optical Measurements and Experimental Investigations in Repeated low Energy Impacts in Powerboat Sandwich Composites
}

\author{
F. Cucinotta ${ }^{\mathrm{a} 1}$, A. Paoli ${ }^{\mathrm{b}}$, G. Risitano ${ }^{\mathrm{a}}$, F. Sfravara ${ }^{\mathrm{a}}$ \\ ${ }^{a}$ Department of Engineering, University of Messina, Contrada Di Dio (S. Agata), 98166 Messina, Italy \\ ${ }^{b}$ Department of Civil and Industrial Engineering, University of Pisa, Largo Lucio Lazzarino 256126 Pisa,, Italy
}

\begin{abstract}
In the world of powerboats competition, the high-performance sandwich-structured composites have completely replaced traditional materials. During the competition, the structure of this kind of ships is subjected to repeated impacts. It is then fundamental to understand the damage evolution in order to select the most appropriate materials and increase safety issues. The present study is aimed at analysing the behaviour of sandwich-structured composites undergoing repeated low-energy impacts. Three different materials have been analysed. Two sandwich-structured composites, for cockpit of offshore powerboats of the UIM (Unione Internationale Motonautique) Championship, differing only by the core cell thickness, and one material simply composed by the skin of the same sandwichstructures, without the core. Impacts were made at three different energy levels: $15 \mathrm{~J}, 17.5 \mathrm{~J}$ and 20 J. In addition to the parameters typically used for the assessment of the impact damage, a new damage assessment has been carried out by means of 3D optical measurements of the imprinted volumes resulting from the impact events. This approach has allowed the definition of a correlation between the imprinted volumes and the number of impacts, until the complete perforation, for each single specimen. Finally, thanks to usual indexes and the imprinted volumes, some considerations are developed about the influence of the core cell thickness in powerboats design.
\end{abstract}

\section{Keywords}

Repeated impacts, damage accumulation, optical measurements, lightweight composites, safety design, offshore powerboats.

\footnotetext{
${ }^{1}$ Corresponding author. Tel.: +39-3289867886; e-mail address: filippo.cucinotta @unime.it
} 


\section{Introduction and background}

The use of composites has increased in many engineering fields in order to improve structural and operational performance. The advantages in the use of composite materials are detailed in [1] and can be summarized in: high values of the strength-to-weight ratio if compared to metals, design flexibility that allows to create almost any shape, flexibility in the mechanical and physical characteristics and, in some cases, a better behaviour in term of environmental impacts [2]. There are also disadvantages that are: complex fabrication processes, low heat resistance and high sensitivity of the fabrication process with respect to the mechanical characteristics. Above all, however, critical issues are represented by the prediction of the failure mode [3] and, in general, the complexity in the prediction of the damage evolution [4]. In this regard, many researchers focused on experimental tests in order to understand the mechanical behaviour of composite materials and to give general laws for the prediction, at early stage, of the possible failure modes, in different stress conditions. An interesting issue is the response of sandwich-structured materials to time-varying loads (fatigue or impact) and the cumulative damage with respect to this type of loads. Many researchers have developed methods to model the total fatigue life [5] with fracture mechanics based delamination growth models [6]. In the case of the impact, there are two possibilities: low velocity and high velocity impact test. In both cases, the first aim of all the studies is the analysis of the influence of different material combinations. Gustin et al. [7] showed the principal advantages by replacing the carbon plies with Kevlar or hybrid ones in terms of absorbed energy and peak force during the tests. Another important feature in the sandwich structures is the influence of the core during the impact. Hassan and Cantwell [8] investigated this influence in the perforation phase, so the energy level was the necessary one to perforate the skin. It is also important to understand the influence of different core materials. Atas and Sevim [9] carried out a comparison between balsa-core and PVC-core (the most used selections). The skin of the sandwich-structured material is the part having a direct contact with the impact. For this reason, Aktaş and Turan [10] investigated the influence of plies of lamination and Sikarwar et al. [11] investigated the impact effects on composite materials with different fibre-orientation. The 
thickness of the laminate, and the type of matrix resin used, influences the behaviour of the sandwich. Sutherland et al. [12] analysed this influence for a orthophthalic and isophthalic resin and reported the different failure modes on the basis of the energy levels (undelaminated, delaminated and fibredamage). The critical condition of composite materials, occurring when visible damages are not present but the structure has absorbed energy from the impact, has been analysed in [13]. This condition typically occurs at low velocity impacts and many authors work in order to find new methodologies to take into account the damages produced by this condition. Some authors tried to define a theoretical approach. Zhu et al. [14] proposed the application of the principle of minimum total potential energy in order to solve the problem of deflection with respect to the impact load for composite sandwich panel subjected to low velocity impacts. Davies and Zhang [15] proposed a new method to predict the internal damage on carbon fibre composite structures under low velocity impact taking into account non-linear effects and in-plane material degradation. Liu [16] proposed a new energy approach to correlate the impact effect with damage process on composite laminates. A further approach consists in the use of impact tests to define indexes and characteristic values of the force in the impact curve. Belingardi and Vadori [17] carried out low velocity impact tests on glass-fibre epoxy composite material and the results were presented by using two different indexes based on absorption energy capacity and two characteristic values of the impact force curve. The same authors carried out a study for the influence of the laminate thickness on the impact response [18] and they proposed a new damage index to estimate the penetration in thick laminates [19]. A single low velocity impact produces a non-visible damage, which is not sufficient to lead the sandwich to the failure. In many applications, however, low velocity impacts are repeated during time and the cumulative damage can lead the material to failure. Belingardi et al. [20] examined the repeated impact tests behaviour on seven laminates characterized by different lay-up sequences and thickness values using the indexes defined in their previous papers. The problem of repeated impacts is very important in all nautical applications, especially for high speed crafts, which require approaches based on computational fluid dynamics due to the complex multiphase phenomena involved [21,22]. 
In particular, high speed crafts involve complex multiphase phenomena as well as ventilation under the hull, thus requiring approaches based on computational fluid dynamics [21,22].

The main goal of the present work is the understanding of the absorbing energy capacity of sandwichstructured composite material used for the cockpits of X-CAT class powerboats in UIM (Union Interantioanle Motonautique) Championship. The specific interest in repeated impact loads on the cockpits, and in particular on the canopies, of the powerboats depends on the collisions with the free surface that occur during a flipping or a capsizing of the boat. In this case, these collisions could lead to a damage of the canopy that it is hardly detectable with a visual analysis but that reduces the mechanical properties of the structure. In this case, the safety of drivers is strongly conditioned by the capacity to absorb energy of the structural materials and by their behaviour to the succession of impacts.

The impact tests were carried in accordance to the ASTM D-07136 standard. Three different materials were considered: two sandwich-structured composite panels, differentiated by the core thickness, and one panel made by the only correspondent skin. For each typology, at least five series of tests have been conducted, showing that the tests have a good repeatability. The impacts were carried out at three different energy levels (15 J, $17.5 \mathrm{~J}$ and $20 \mathrm{~J}$ ) with a maximum energy level of $20 \mathrm{~J}$ as reported by Belingardi [17] until reaching the complete perforation of the upper skin, for a total of 333 impacts. Results are presented in terms of usual indexes and new ones in accordance to a previous study [23]. An optical scanner was used to obtain 3D measurements of the imprinted volumes resulting from the impact events. This approach allows to analyse the influence of the core thickness on the response to low velocity impacts by correlating imprinted volumes with absorbed energy. The proposed technique is suitable for more detailed investigations. For example, it can be used to define shape parameters of the damage or to investigate surface damage not perceptible by visual analysis only. 


\section{Materials and methods}

The tested materials are sandwich-structured composites made by the Hand Lay-Up technique. This manufacturing technique requires the processing of the resin by catalysts and accelerators. Thereafter, the resin is laid by hand on fabric with rollers and paintbrushes. In this paper, a sandwich-structured composite panel with a core cell thickness of $20 \mathrm{~mm}$ (Type A), a sandwich-structured composite panel with a core cell thickness of $30 \mathrm{~mm}$ (Type B), and a single skin only panel without the core cell (Skin), are considered. Square-shaped samples $(100 \times 100 \mathrm{~mm})$ have been manufactured by a specialized shipyard in Abu Dhabi (see Fig. 1). Tab. 1 summarizes the lamination layers of the three tested materials along with their overall thickness and density values.

Impact tests have been carried out by using the CEAST Fractovis Plus machine. The impact energy has been managed by the height variation of the striker and through the impact speed. The testing machine measures the load on the indenter as a function of time $F(t)$. The impact speed can be obtained as:

$$
v(t)=v_{F}+\int_{t}\left(\frac{F(t)}{m}+g\right) d t
$$

where $v_{F}$ is the speed measured at the instant before impact and $m$ is the total mass of the striker. It is possible to determine the impact energy as:

$$
E(t)=\int_{t} F(t) v(t) d t
$$

The striker used has a hemispherical shape with a diameter equal to $20 \mathrm{~mm}$ and a total mass of 6.5 $\mathrm{kg}$. The three energy levels of the repeated impacts are $15 \mathrm{~J}, 17.5 \mathrm{~J}$ and $20 \mathrm{~J}$. After every single impact, an estimate of the imprinted volume has been obtained by using the ATOS-3D Scanner (GOM). 


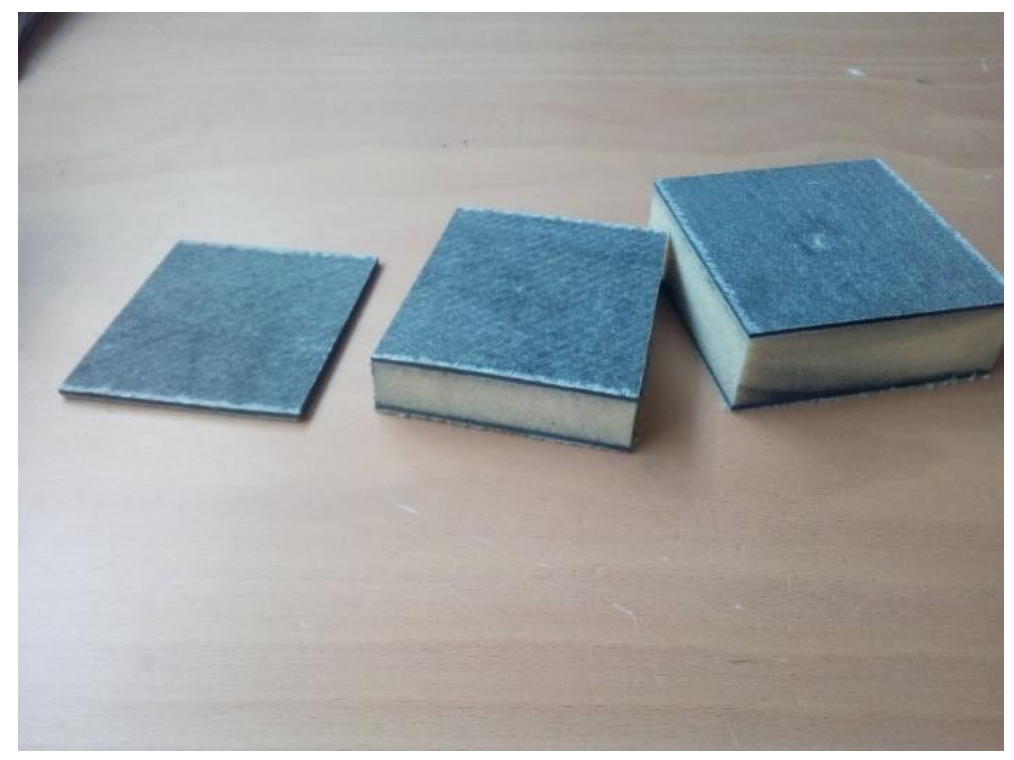

Fig. 1 Samples of the three specimens adopted for the experimental tests: "Skin" on the left side; "Type A" in the middle and "Type B" on the right side.

Tab. 1 Lamination layers of the three tested materials (- present in the specimen; / not present in the specimen), along with their overall thickness and average density values.

\begin{tabular}{|c|c|c|c|c|c|c|c|}
\hline Ply & Material & Weave & Orientation & $\begin{array}{c}\text { Areal weight } \\
{\left[\mathrm{g} / \mathrm{m}^{2}\right]}\end{array}$ & Type A & Type B & Skin \\
\hline 1 & E-Glass Mat & Mat & Random & 300 & - & - & - \\
\hline 2 & Carbon & Twill 2x2 & $45 / 45$ & 407 & - & - & - \\
\hline 3 & Carbon & Quadriaxial & $0 / 45 / 90 / 45$ & 807 & - & - & - \\
\hline 4 & Carbon & Twill 2x2 & $45 / 45$ & 407 & - & - & - \\
\hline 5 & CoreCell PVC & - & & & $20 \mathrm{~mm}$ & $30 \mathrm{~mm}$ & I \\
\hline 6 & Carbon & Twill 2x2 & $45 / 45$ & 407 & - & - & I \\
\hline 7 & Carbon & Quadriaxial & $0 / 45 / 90 / 45$ & 807 & - & - & I \\
\hline 8 & Carbon & Twill 2x2 & $45 / 45$ & 407 & - & - & I \\
\hline 9 & Kevlar & Twill $2 \times 2$ & $0 / 90$ & 175 & - & - & l \\
\hline \multicolumn{5}{|c|}{ Overall thickness [mm] } & 26.0 & 35.5 & 3.4 \\
\hline \multicolumn{5}{|c|}{ Average density $\left[\mathrm{kg} / \mathrm{m}^{3}\right]$} & 357 & 343 & 1097 \\
\hline \multicolumn{5}{|c|}{ Mass [g] } & 93 & 121 & 37 \\
\hline
\end{tabular}

In powerboats, the outer side is the one with glass (Fig. 2-a), while the internal side is the one with Kevlar (Fig. 3-b). Kevlar is used inside for its reduced brittleness compared with carbon, thus lowering the risks for the pilots in case of breakage of the canopy. The glass is used outside for its better workability, having to follow the shapes of the mould, and for the good capability to resist the external environment. The impact tests have been carried out on the glass side. 


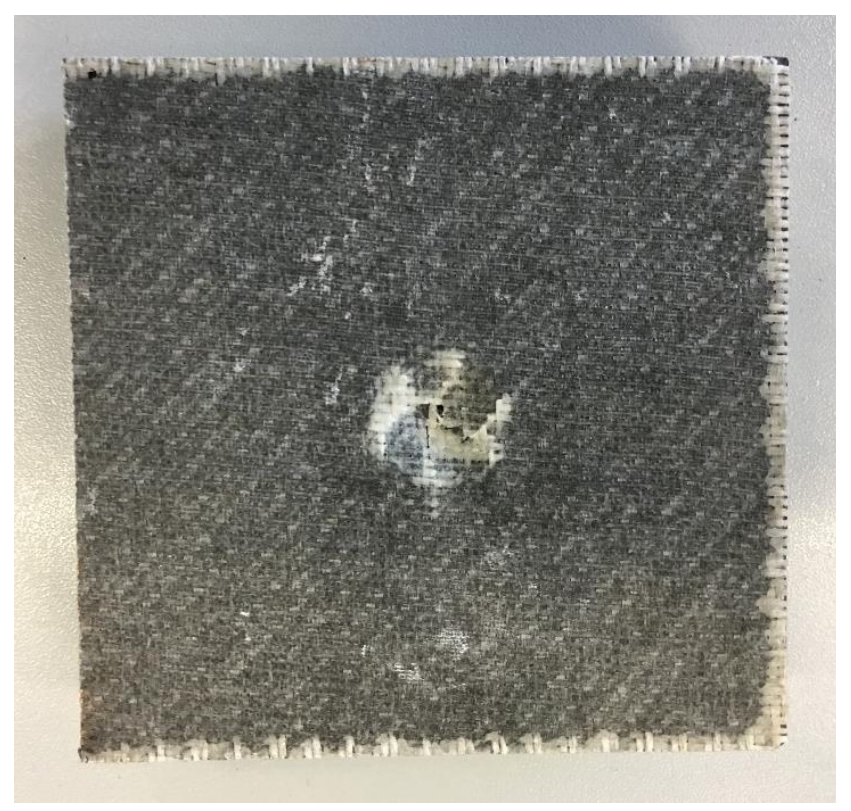

(a)

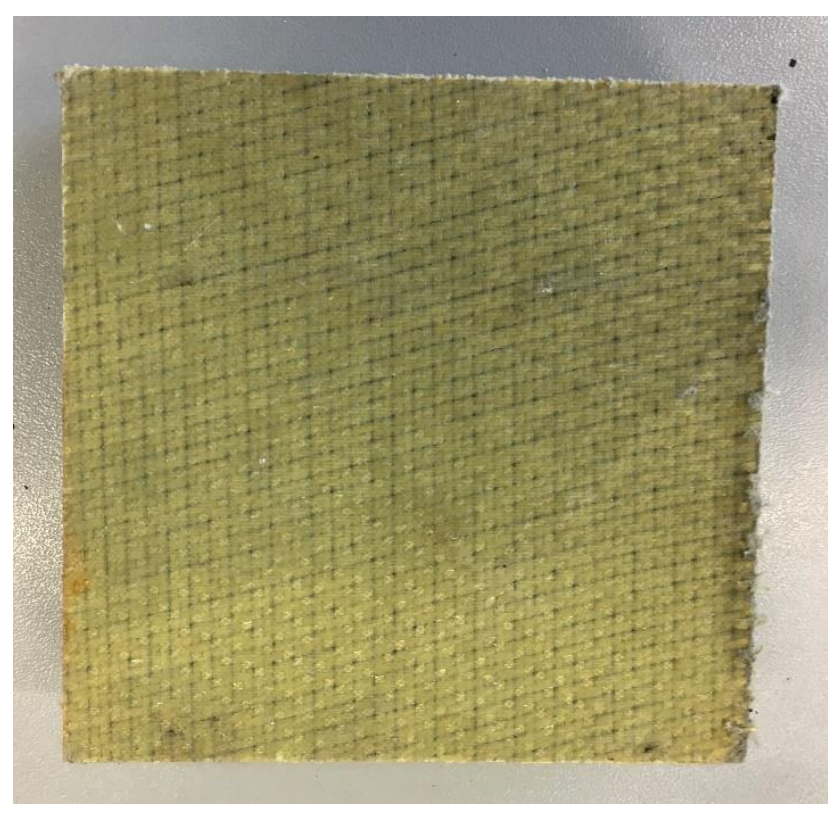

(b)

Fig. 2 Specimen's outer (a) and inner (b) side. In the outer side it is possible to observe the imprinted volume.

Fig. 3 shows the clamping apparatus, specifically designed in order to guarantee the same impact point for all the repeated tests. It consists of two flanges, which enclose the specimen. The two flanges have a $70 \mathrm{~mm}$ diameter central hole, which allows the penetrator to freely impact on the upper face of the specimen. The specimen is fully clamped between the flanges to prevent translation or rotation movements. The clamping apparatus has a mass of $3.55 \mathrm{~kg}$.

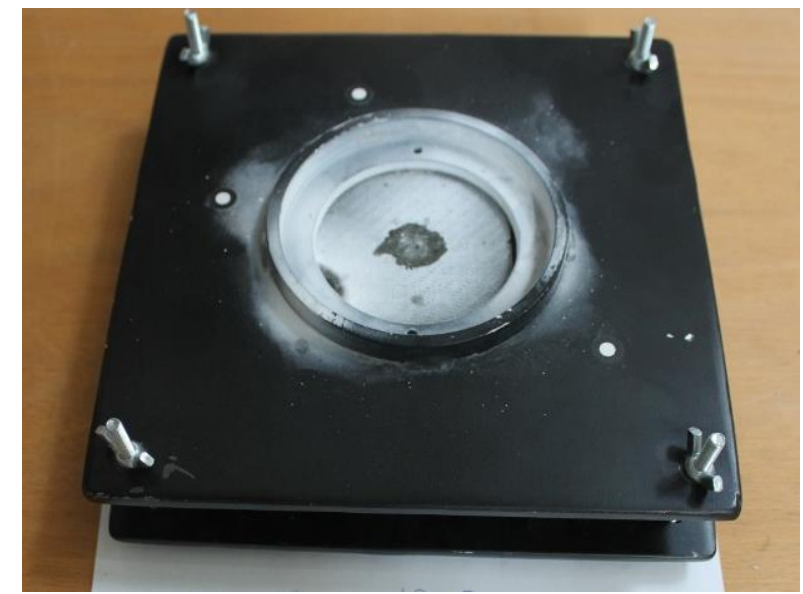

(a)

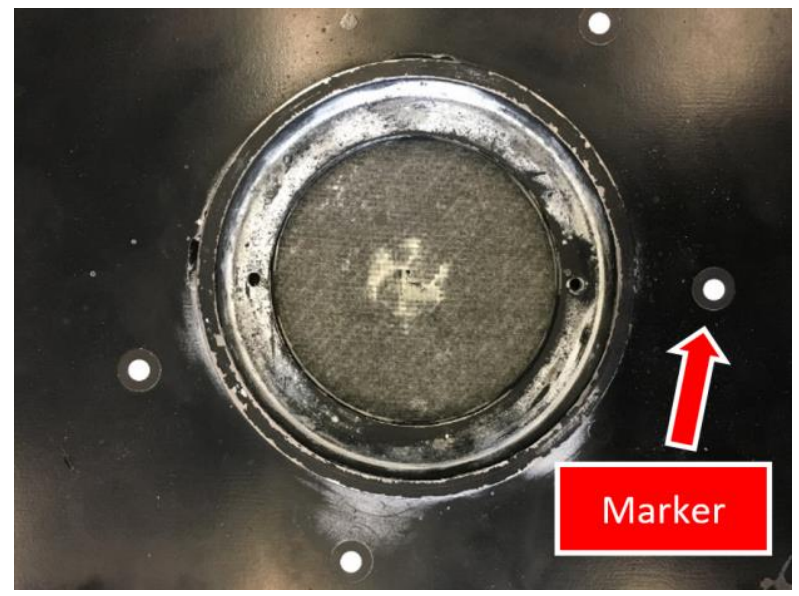

(b)

Fig. 3 (a) The clamping apparatus used for the experimental tests. Circular markers, surrounded by black ring, are visible on the upper side of the apparatus, $(b)$ detail of the specimen constrained within the clamping system. It is possible to note the markers for the $3 D$ scanner. 
The 3D optical scanner (Fig. 4), composed of a structured blue-light projector and two cameras, performs high-speed, accurate scans with a detailed resolution (in the order of hundredths of millimetre).

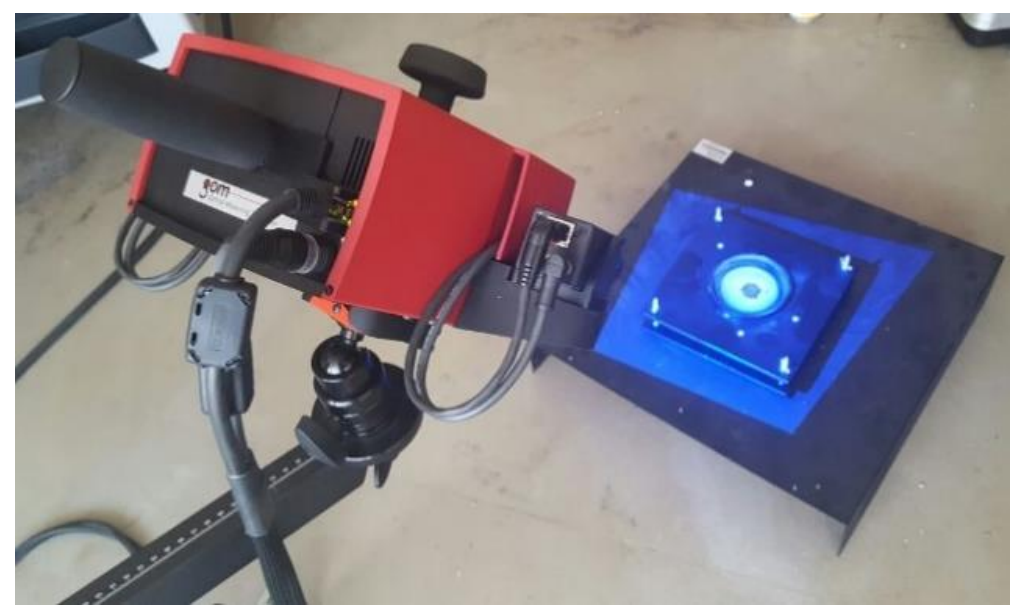

Fig. 4 The ATOS-3D scanner adopted for the optical measurements of the specimens

It exploits the triangulation method to obtain point clouds from the acquired surfaces (Fig. 5 - a). A tessellation process is then performed in order to obtain a polygonal mesh (StL model) (Fig. 5 - b). After the polygonal mesh creation, a NURBS (Non-Uniform Rational B-Splines)-based reconstruction process is performed (Fig. 6). The surface reconstruction saves time during the acquisition phase, as an average of 3 scans is adequate, and in the post processing, as it is not required to repair the mesh by closing holes and removing singularities. In addition, the NURBS surfaces allow a greater freedom in the comparison of volumes between successive impacts for the estimations of the damage. A greater number of scans, up to 5, is necessary when the number of impacts increases and consequently the indentation depth. Markers have been used to align the different scans. A classical reconstruction pipeline (filtering, sampling and marching cube tessellation) [24] is used to obtain the StL digital representation of the impacted specimen surface. 


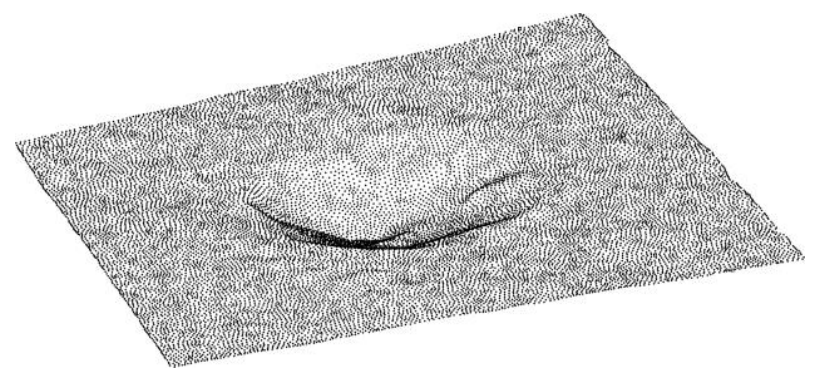

(a)

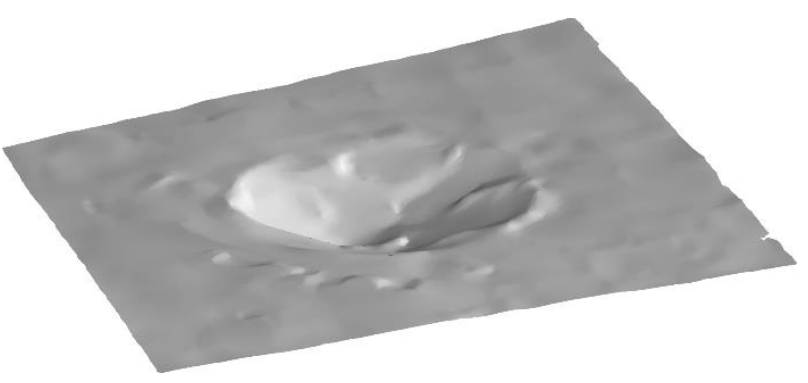

(b)

Fig. 5 (a) Point cloud as obtained by the 3D optical scanner and (b) the StL representation obtained by a tessellation process.

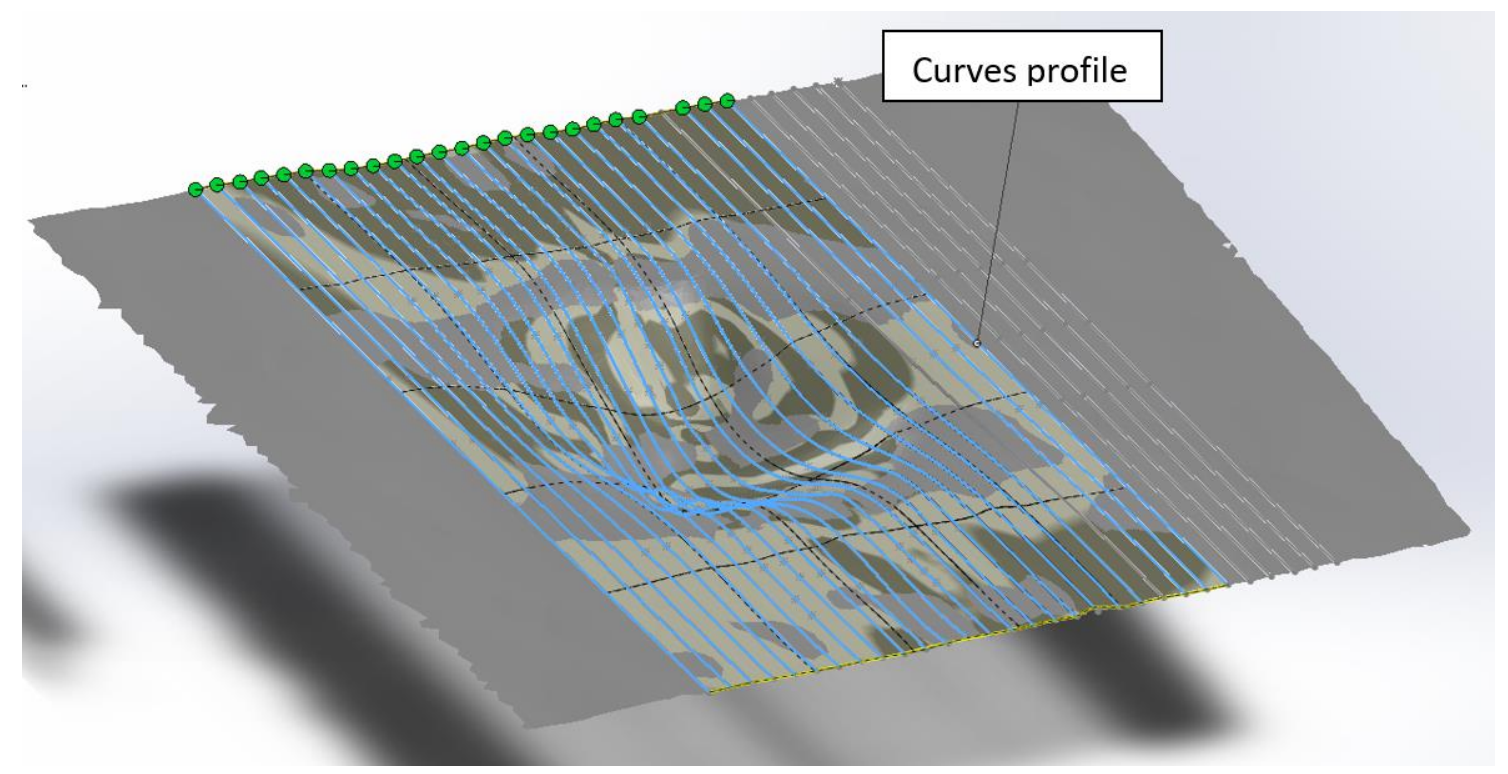

Fig. 6 Nurbs-based reconstruction of the impacted specimen.

During the actual stage, the reconstruction precision is an important issue; an accurate deviation analysis between the mesh surface and the reconstructed CAD-Surface has been done. The reconstructed surface has been obtained by a Loft procedure. The better way to reduce the deviation from the original mesh is to analyse each curve. An example is reported in Fig. 7 and Fig. 8: the initial maximum deviation of the curve with respect to mesh is $0.189 \mathrm{~mm}$ (Fig. 7) and, thanks to the control parameters, is reduced to $0.0211 \mathrm{~mm}$ (Fig. 8). 


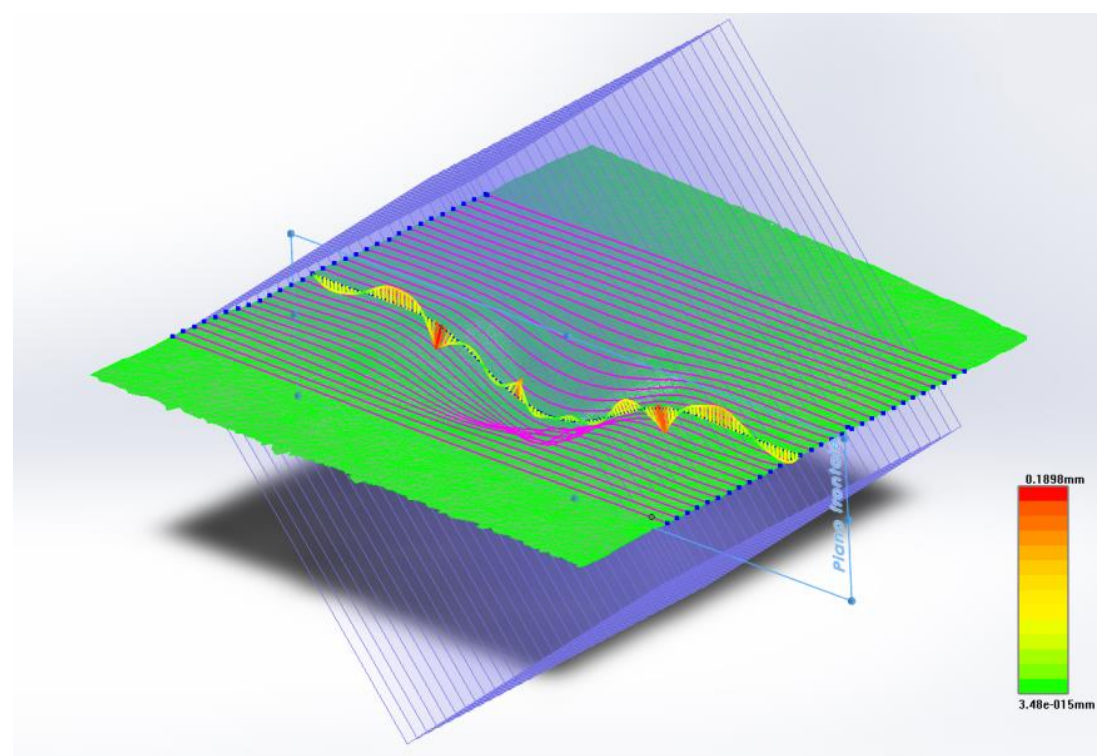

Fig. 7 Section curves on the polygonal mesh with the deviation analysis before control.

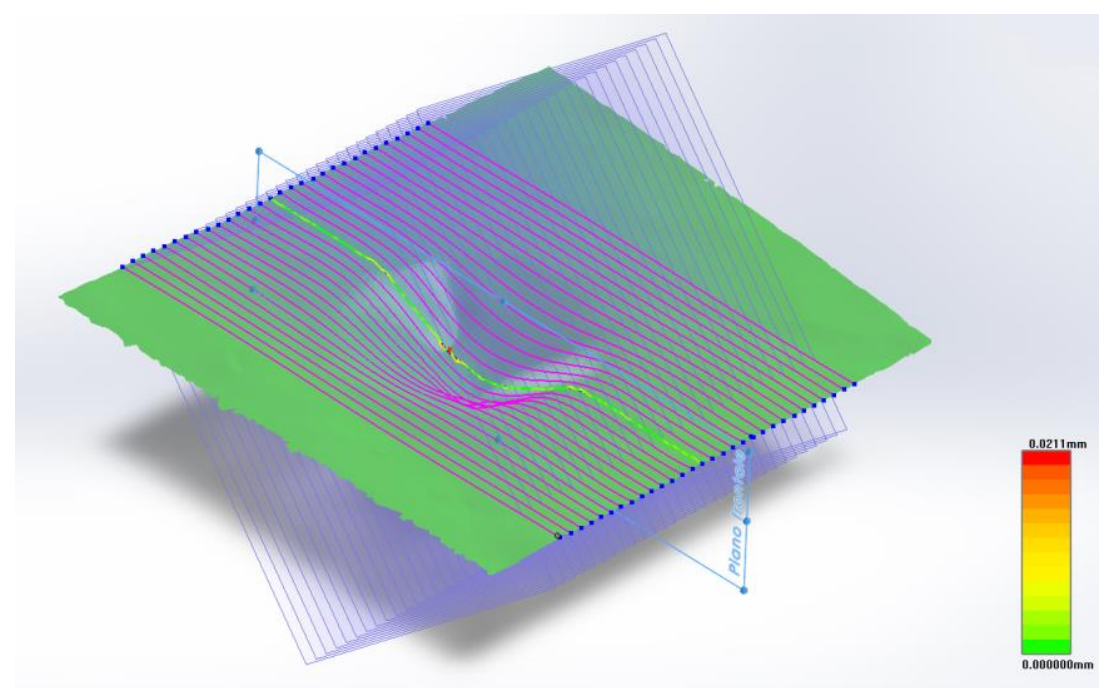

Fig. 8 Section curves on the polygonal mesh with the deviation analysis after control.

After the reconstruction of the CAD-Surface, a deviation analysis has been performed (deviation average in the order of thousandth of a millimetre (Fig. 9)). 


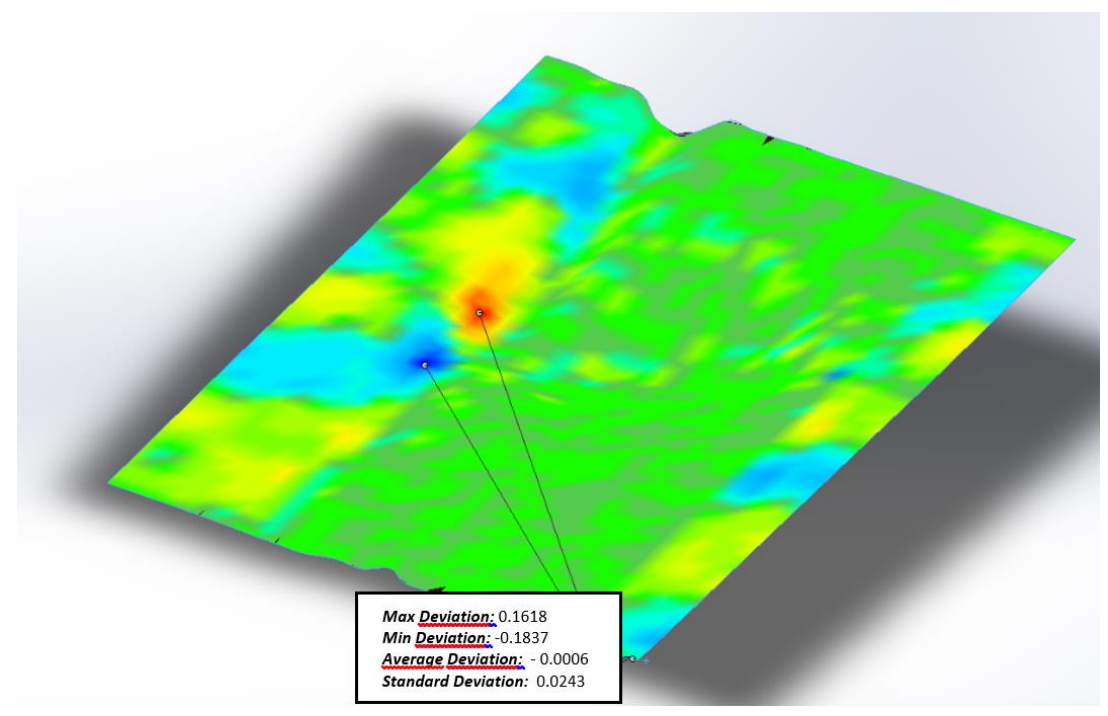

Fig. 9 Maximum, minimum and average deviation values.

This procedure keeps the reconstruction accuracy under control in the area of interest. Minimum and maximum deviation peaks are always out of the impact zone (Fig. 9). It is then possible to evaluate the volume of indenter impression after each single impact by the above-described CAD-based reconstruction.

\section{Results and Discussion}

Five specimens have been tested for each energy level (15 J, $17.5 \mathrm{~J}$ and $20 \mathrm{~J}$ ) and for each material in order to verify the results repeatability. Repeated impact stage has been conducted at constant impact energy level until the breaking of the upper skin. Important parameters are the maximum load capacity (peak force) of the material and the maximum displacement, defined as the maximum indenter penetration. This value is reached in the plastic phase of penetration; therefore, it is greater than the final depth of the imprinted volume. Another parameter is the damage degree, which is defined as the ratio between the energy absorbed by the material (absorbed energy) and the energy provided by the impact machine. The damage degree is a significant parameter. It tends towards the value of 1 with the increasing of the number of impacts. When it is near this value, it means that the material has absorbed almost the entire amount of energy provided by the machine and, therefore, there is not a rebound of the striker. Consequently, a perforation is present on the specimen. The 
visible impact damage on the specimen has been evaluated by the $3 \mathrm{D}$ scanner. The volume of the indenter imprint due to the plastic deformation has been investigated (imprint volume). The 3D optical scanner allows the acquisition of the imprinted surface with a certified precision of $0.01 \mathrm{~mm}$. During the reconstruction process, each curve of the loft-procedure presents a maximum deviation of $0.02 \mathrm{~mm}$. The loft-based reconstructed surface is very near to the actual surface. In the impacted area, the absolute deviation is always under $0.01 \mathrm{~mm}$. In any case, the peak of the deviation is always outside this region and under $0.2 \mathrm{~mm}$. In general, the average of the deviation values is about 0.005 $\mathrm{mm}$ and the standard deviation is always under $0.03 \mathrm{~mm}$. Fig. 10 shows the average value of peak forces versus the repeated impact number of the three tested materials. Relative regression curves are also reported. In all the following figures, the spread of the results has been shown by introducing error bars describing the standard deviation values of the relative plotted parameters. When there is only one unperforated specimen, the error bar is not reported in the graphs. This occurs, obviously, for large impact numbers.

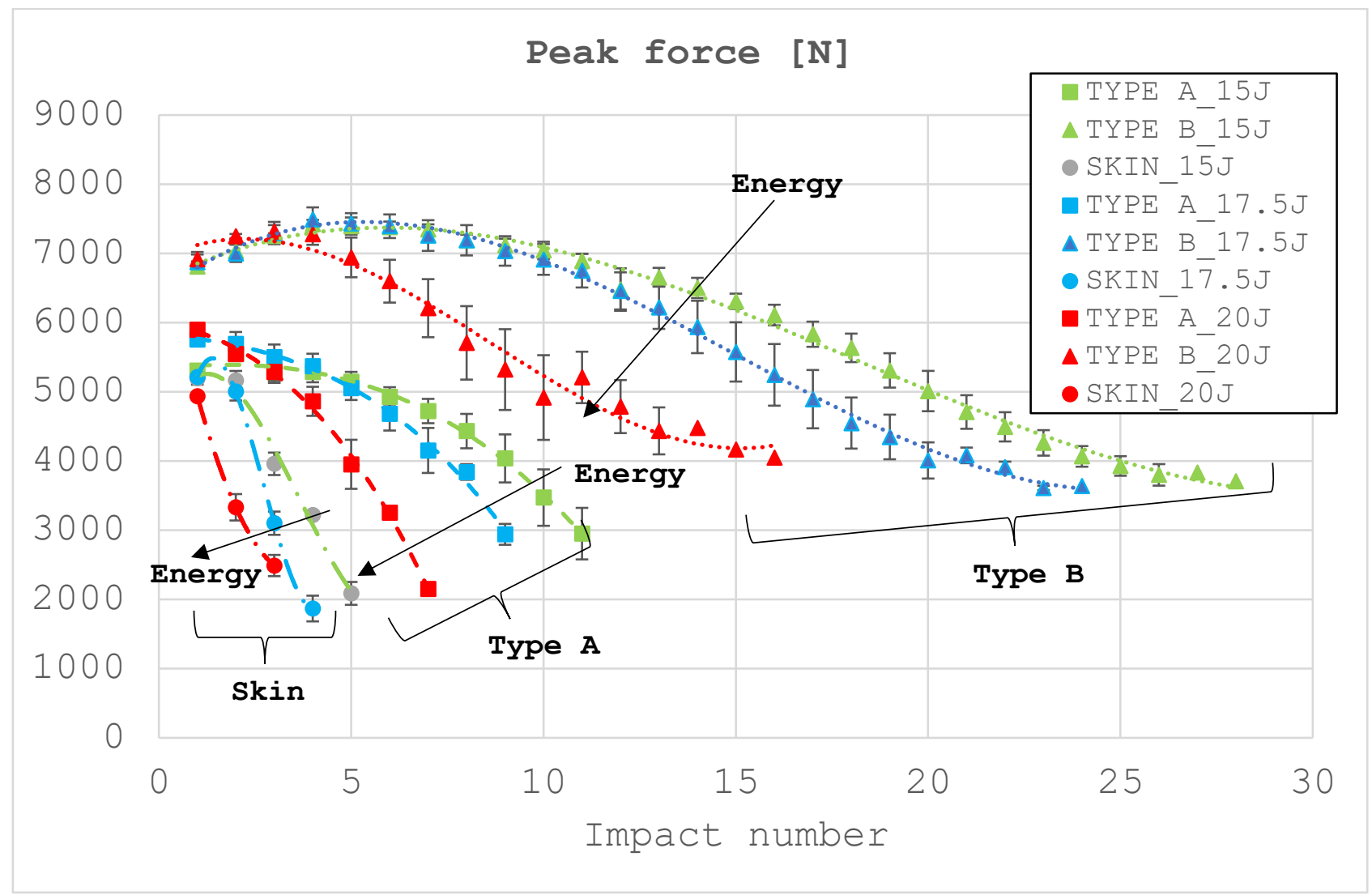

Fig. 10 Peak forces versus impact number. 
It is possible to note that the matching regression curve accurately models the measurements, with a minimal data spread. For all the materials, the regression is a cubic law. The Type B resists to more impacts, since it has a greater core thickness. For all the materials, the number of impacts is reduced at the increasing of the energy level. Only for Type B, the first impacts show an increase of the peak force.

These effects are well visible in Fig. 11, by comparing, for example, the force values in the 1st, the 5th and the 27 th impact, on the same Type B specimen, at $15 \mathrm{~J}$. In the 1 st impact there is a total rebound of the indenter. The curve of the 5th impact has a higher peak force, although its stiffness (the slope at the origin) and the energy absorbed (proportional to the subtended area) are lower. In the same figure, it is visible the different behaviour after the peak load. In the case of the 1 st impact curve, a zig-zag area, due to the damage of the fibres, can be observed. This zone is not present in the other curves, which are smoother, since the integrity of the fibres is already compromised. In the 27 th impact curve the peak force it is much lower because there is a perforation of the skin and there is no rebound since the curve does not return to zero displacement.

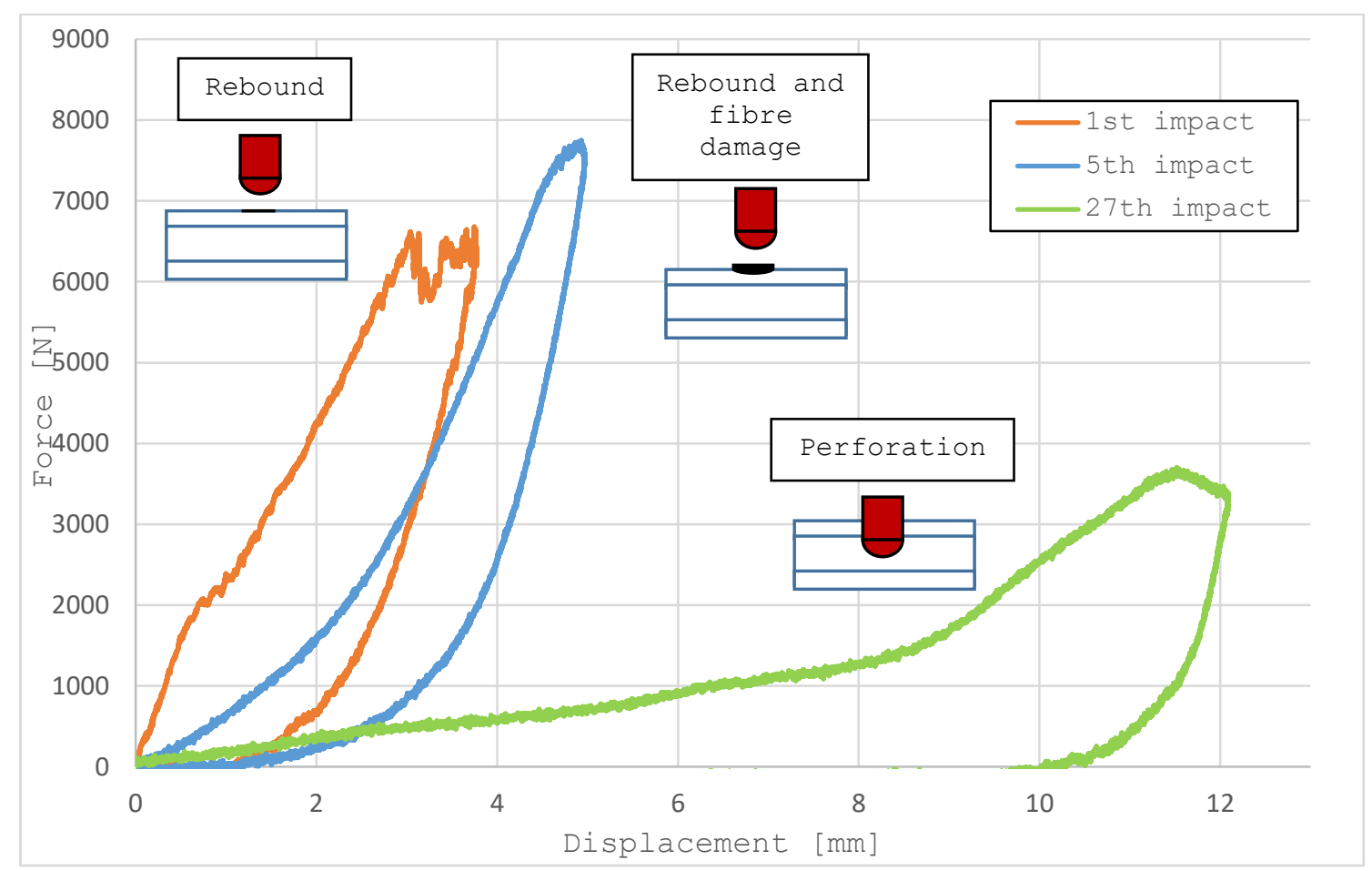

Fig. 11 A comparative example between the 1 st and the 5th and the 27th impact on the same Type B specimen (tests at $15 \mathrm{~J})$. 
Fig. 12 shows the average stiffness values, defined as the value of the slope at the origin of the forcedisplacement curve, versus the repeated impact number of the three tested materials. The stiffness is not significantly influenced by the impact energy, but it depends on the number of impacts. For all the materials, the regression is an exponential law. For the skin, the variation of the impact energy does not change significantly the stiffness. Indeed, as can be seen, the three curves are almost completely overlapping (see Fig. 13). The Type A and Type B have a strong decrease of the stiffness after the first impacts and it stabilizes with an asymptotic behaviour. It is worth noting that the stiffness does not significantly depend on the impact energy since it is an intrinsic characteristic of the material and the standard deviation of the results is extremely limited.

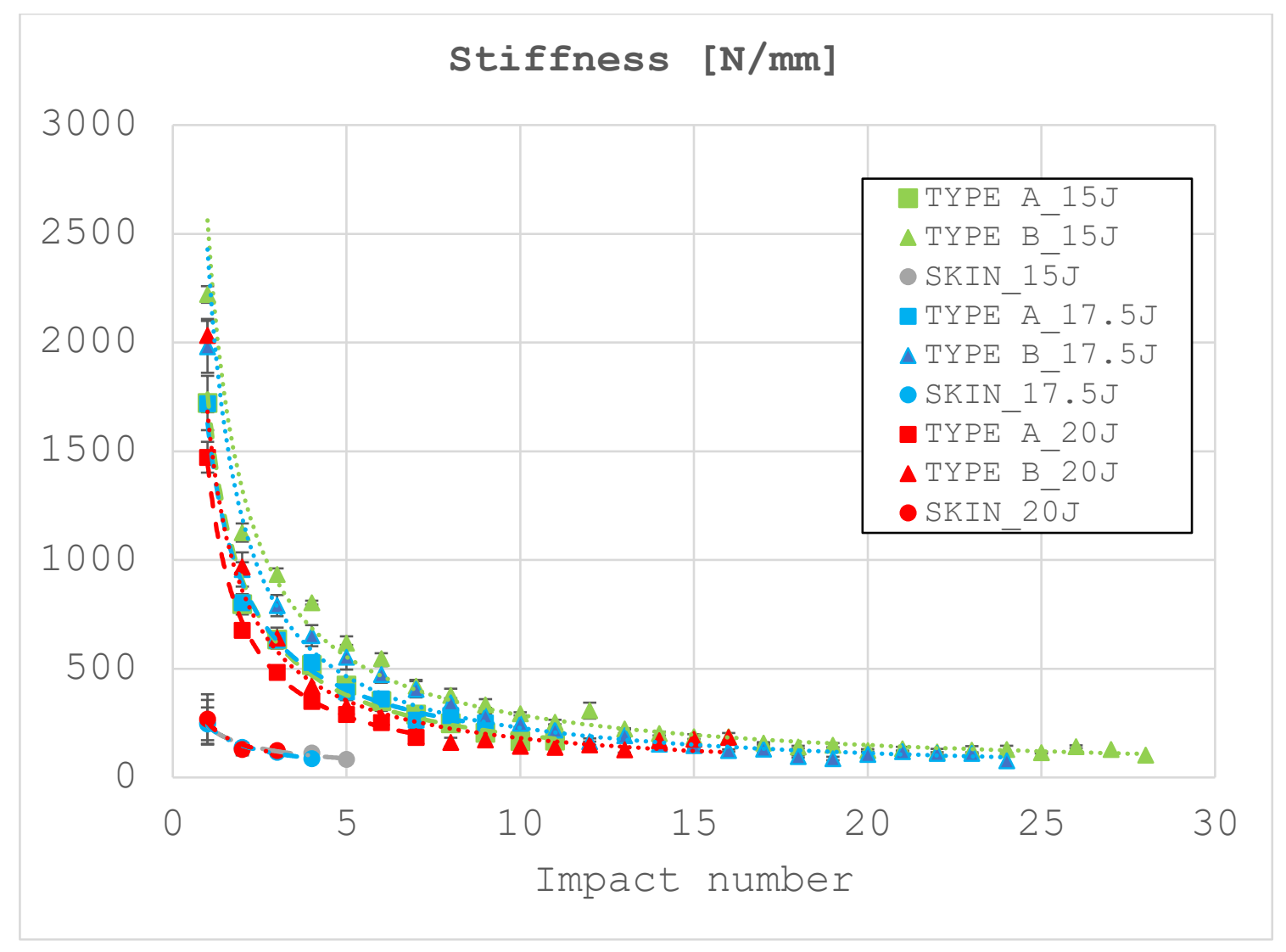

Fig. 12 Stiffness versus impact number. 


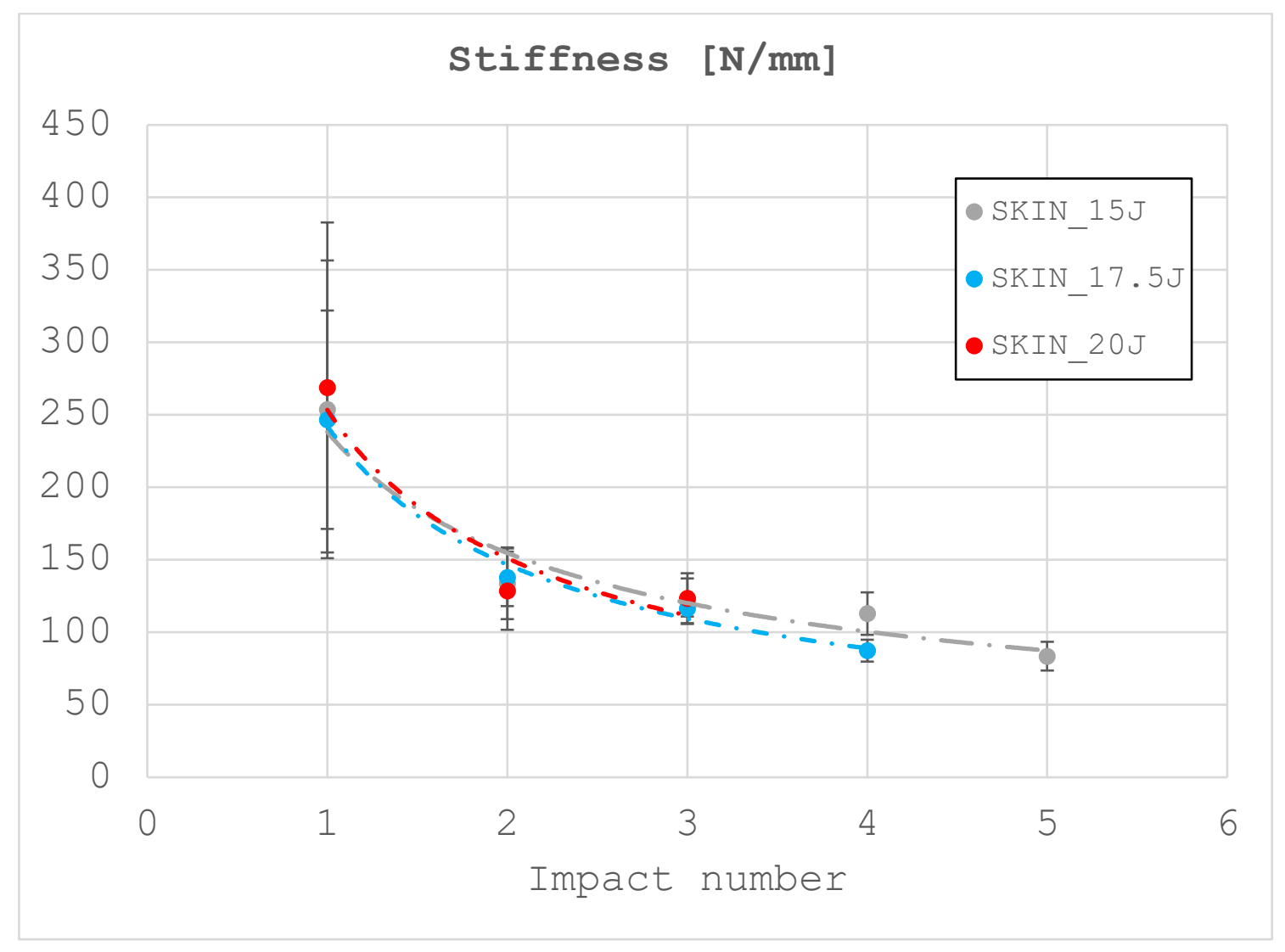

Fig. 13 Stiffness vs impact number, particular with only the Skin curves.

Fig. 14 shows the average values of damage degree versus the repeated impact number. For all the materials, the damage degree more quickly reaches its limit value by increasing the energy level of the impacts. The three materials have a dissimilar behaviour: the Skin has a linear trend while the Type A and Type B have a parabolic trend although substantially different. This difference clearly depends on the core thickness. As the thickness increases, the plots tend to be lower and more concave, highlighting the greater capability of the material to absorb energy before failure. 


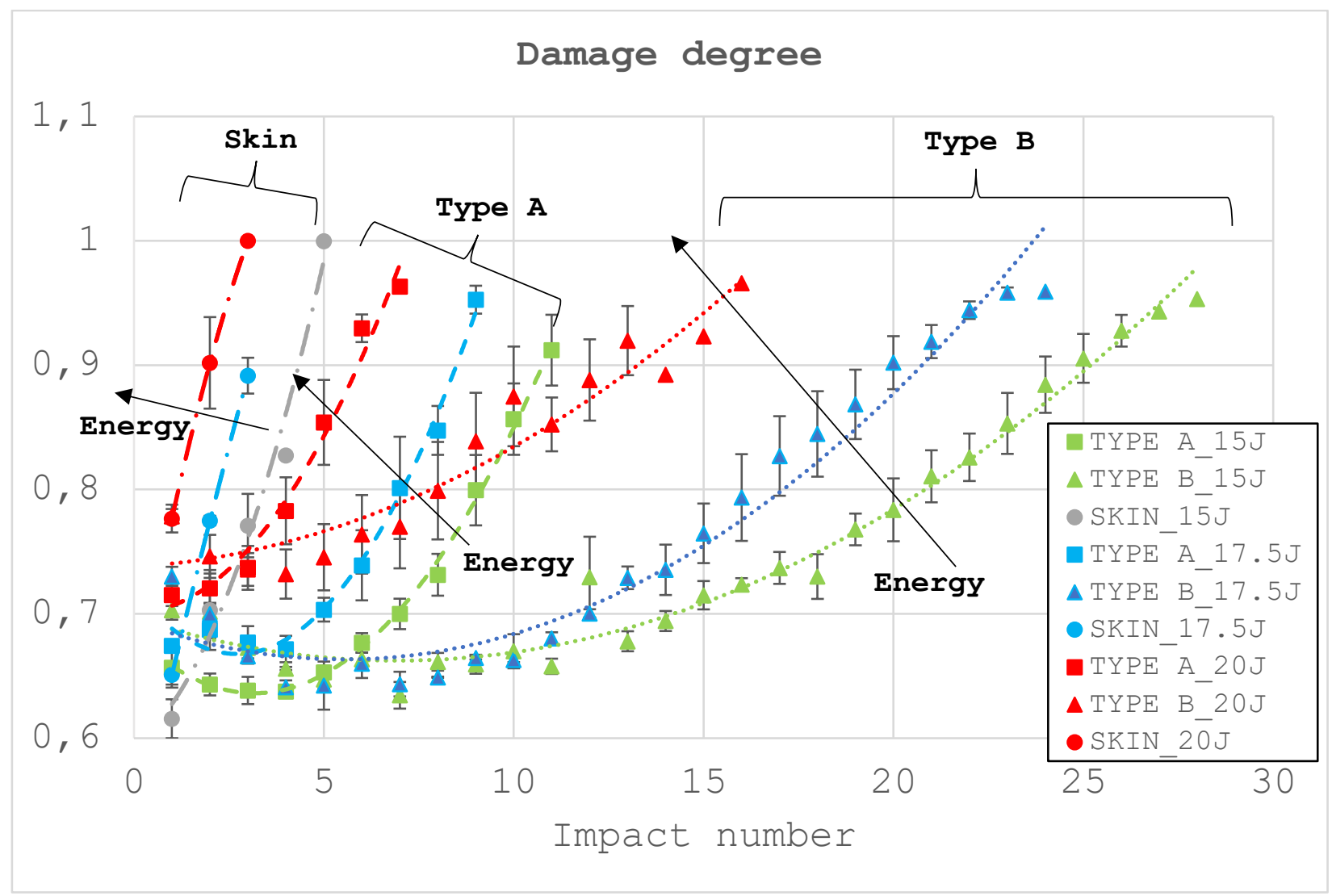

Fig. 14 Damage degree versus impact number.

Fig. 15 shows the average values of imprint volume versus the repeated impact number. For all the materials, the imprint volume linearly grows with increasing impact number. For Type $\mathrm{B}$, the behaviour $20 \mathrm{~J}$ strongly deviates from those obtained by $15 \mathrm{~J}$ and $17.5 \mathrm{~J}$. The behaviour of the imprint volume is associated to that of the maximum displacement (Fig. 16). Indeed, both have a linear trend by increasing the impact number. However, it is interesting to note that in the case of the maximum displacement, the Skin presents values much higher (double) if compared to those obtained for Type A and Type B, due to the absence of the core. The same thing cannot be stated for the imprint volume since all the materials have similar values. 


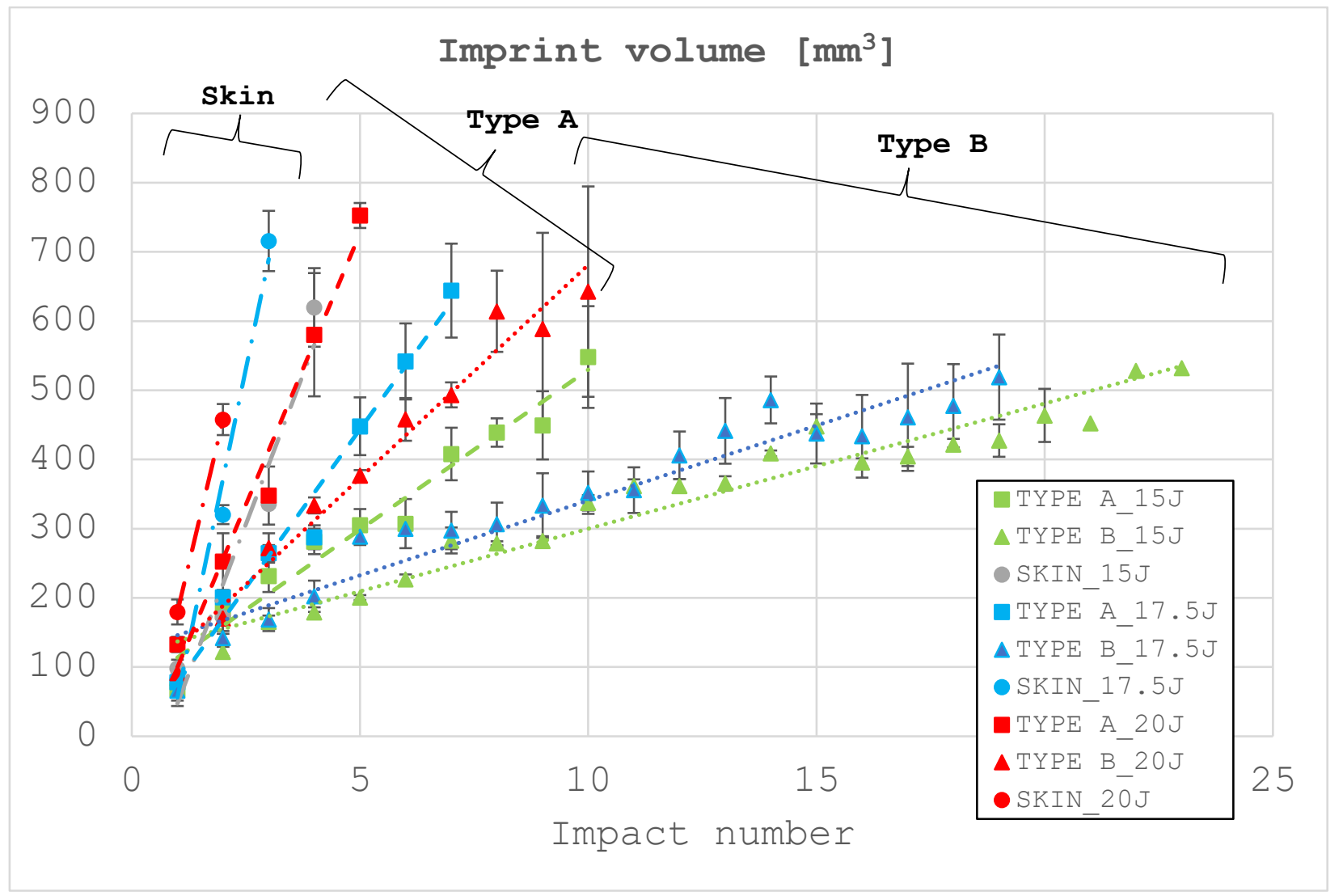

Fig. 15 Imprint volume versus impact number.

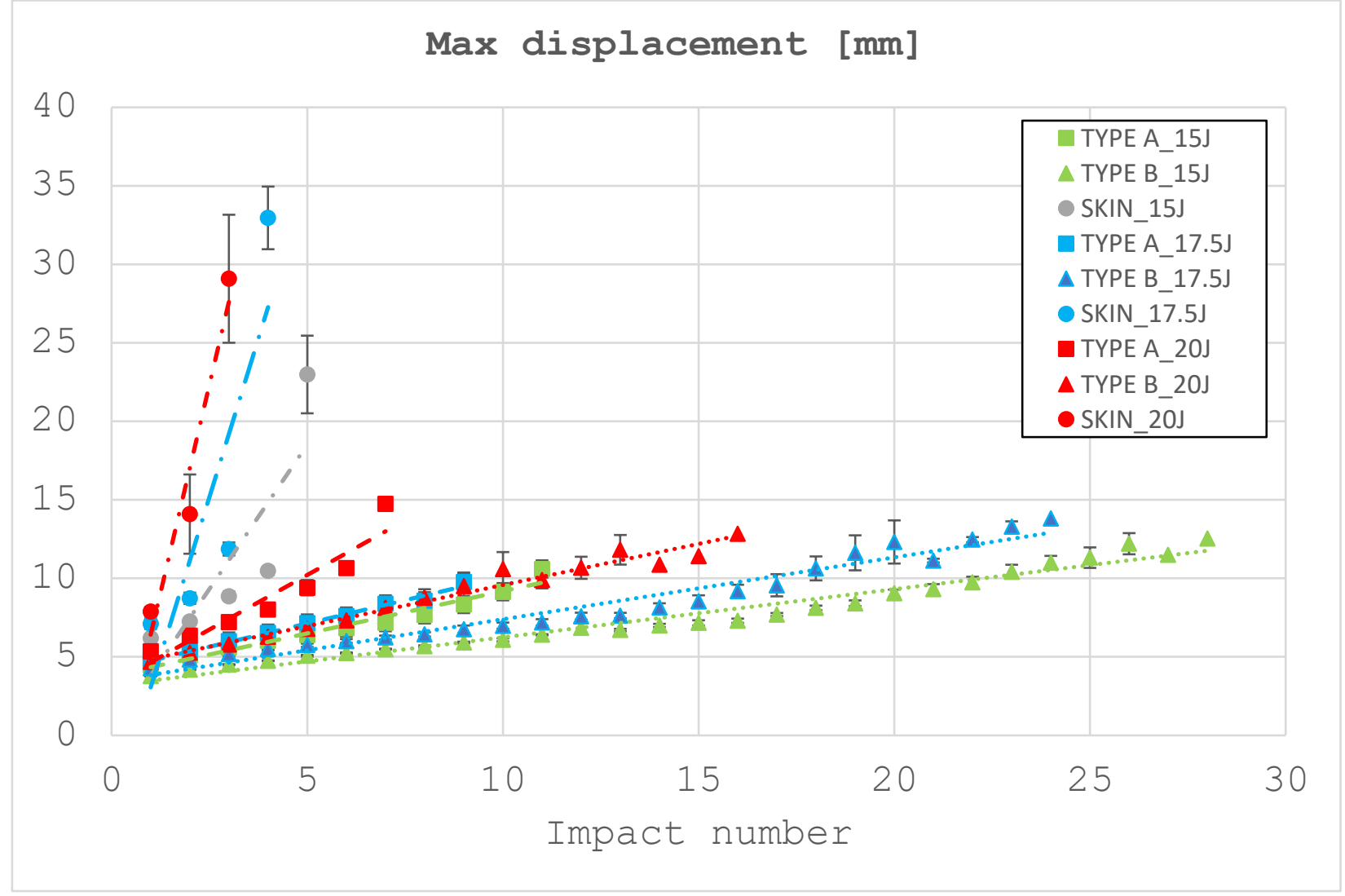

Fig. 16 Maximum displacement versus impact number. 
Fig. 17 shows the average values of absorbed energy versus the repeated impact number of the three tested materials. As in the case of the damage degree, also the absorbed energy presents nonlinear trends, which are dissimilar from material to material. In the specific case, the Skin has an inverse curvature with respect to Type A and Type B materials. It is worth noting that the linear trend of the imprint volume is different with respect to the trend of the absorbed energies since the samples are sandwich composites laminates. Therefore, the absorbing energy capability is not proportional to the impact number, unlike the imprint volume.

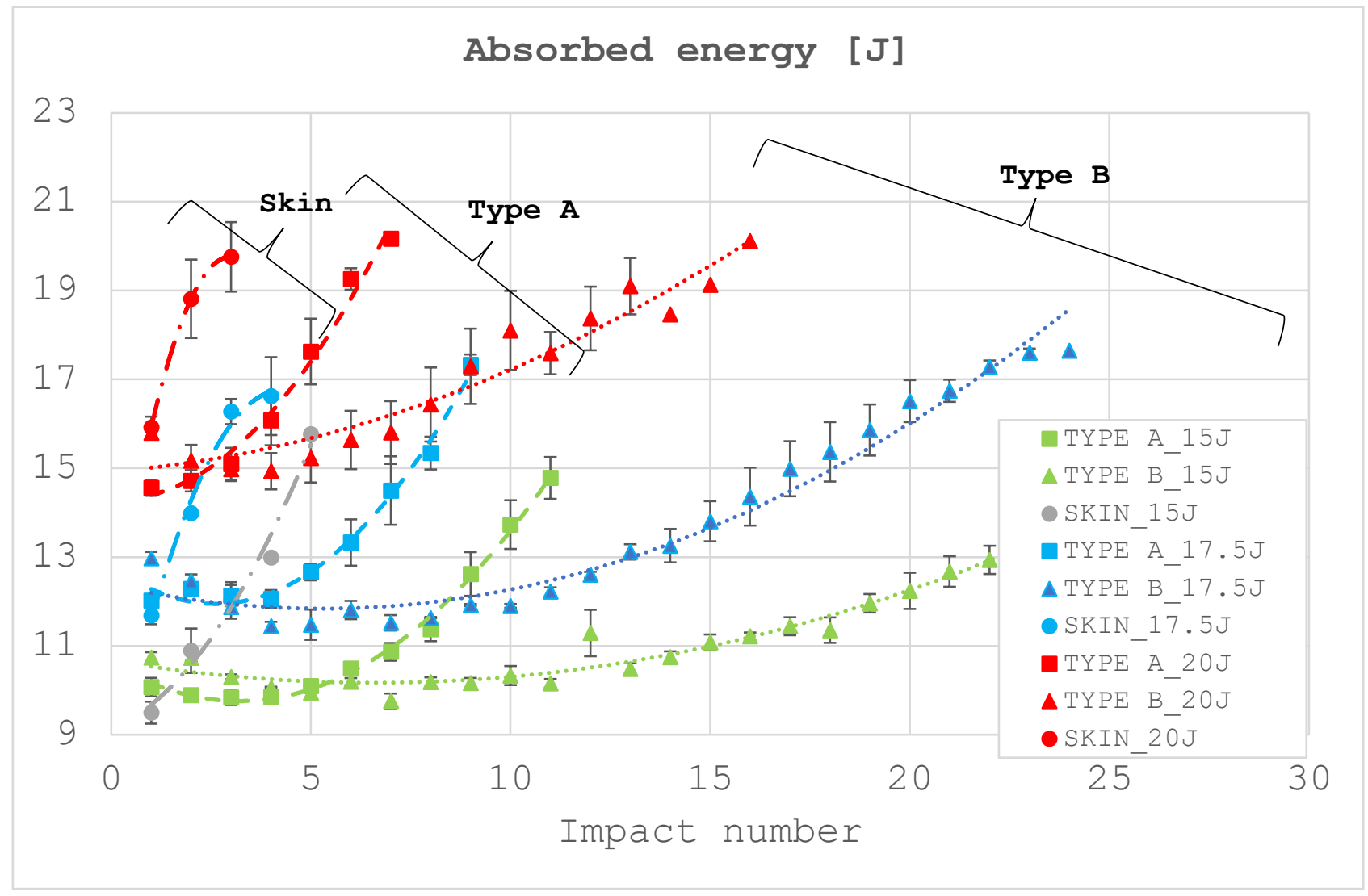

Fig. 17 Absorbed energy versus impact number.

Finally, by way of summary, Fig. 18 shows the average values of the impact number versus the impact energy. As can be seen, the trends of the three materials are similar. Clearly, the Type B material is resistant to a greater number of impacts. The double core cell thickness dramatically improves impact properties. Indeed, the Type A has a behaviour close to the Skin. This circumstance evidences the 
importance of the core cell thickness for the design of sandwich-structured composites used for offshore powerboats. In the Tab. 2, for each quantity reported in the graphs from Fig. 10 to Fig. 17, has been reported curve typology and the correlation coefficients $\mathrm{R}^{2}$.

Tab. 2 Summary table of the curve typology and correlation coefficients for each curve.

Type A

Type B

Skin

\begin{tabular}{|l|l|rrr|rrrrrr|}
\hline Quantity & Curve typology & $\mathbf{1 5} \mathbf{J}$ & $\mathbf{1 7 . 5} \mathbf{J}$ & $\mathbf{2 0} \mathbf{J}$ & $\mathbf{1 5} \mathbf{J}$ & $\mathbf{1 7 . 5} \mathbf{J}$ & $\mathbf{2 0} \mathbf{J}$ & $\mathbf{1 5} \mathbf{J}$ & $\mathbf{1 7 . 5} \mathbf{~ J}$ & $\mathbf{2 0 ~ J}$ \\
\hline Peak force & 3rd order polynomial & 0.994 & 0.995 & 0.997 & 0.994 & 0.996 & 0.975 & 0.987 & 1.000 & 1.000 \\
Stiffness & Exponential & 0.984 & 0.986 & 0.994 & 0.981 & 0.968 & 0.916 & 0.939 & 0.986 & 0.897 \\
Damage degree & 2nd order polynomial & 0.997 & 0.988 & 0.979 & 0.976 & 0.960 & 0.919 & 0.976 & 1.000 & 1.000 \\
Impress volume & Linear & 0.961 & 0.977 & 0.976 & 0.944 & 0.921 & 0.973 & 0.931 & 0.980 & 1.000 \\
Max. displacement & Linear & 0.960 & 0.990 & 0.902 & 0.968 & 0.955 & 0.966 & 0.730 & 0.751 & 0.946 \\
Absorbed energy & 2nd order polynomial & 0.995 & 0.988 & 0.984 & 0.980 & 0.967 & 0.925 & 0.978 & 0.988 & 1.000 \\
\hline
\end{tabular}

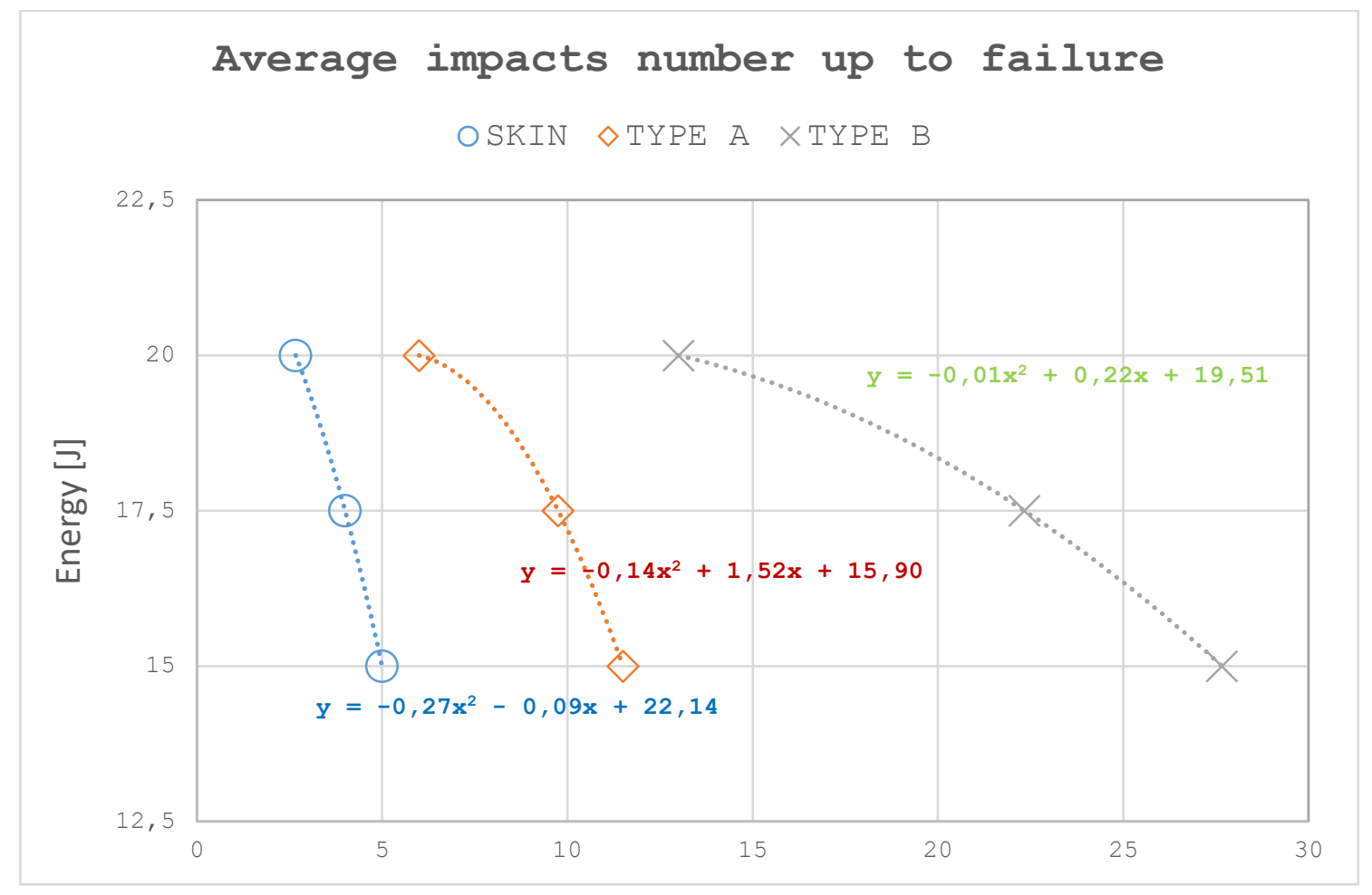

Fig. 18 Impact energy versus average impacts number up to failure.

\section{Conclusions}

Three composite materials used in X-CAT class of UIM boat racing have been tested. The first two are sandwich-structured composites, only differing by the core thickness. The third material is made 
by the same skin without core. The experimental tests consist of impacts repeated at constant energy levels. A custom clamping apparatus ensures that each impact is exactly over the previous. The imprint plastic volume of each impact has been detected by a 3D optical scanner, in order to evaluate both indenter displacements and true plastic deformations. For each typology, at least five series of tests have been conducted, showing that the tests have a good repeatability.

The composite stiffness exponentially decays with a reduction of the peak force at the increasing of the impact number. Instead, the absorbed energy grows in a parabolic way, until failure.

The optical measurements proved to be a valuable tool to estimate the impact effects. The detected imprint volume linearly increases by increasing the impact energy and the correlation between imprint volume and absorbed energy is not linear. The core cell thickness is a significant parameter for the design stage since it influences energy absorbing capability and the number of impacts before failure.

\section{Acknowledgements}

Authors wish to thank the Unione Internationale Motonautique for providing the samples and Mr. Sergio Abrami for the precious comments and suggestions.

\section{References}

[1] Gibson RF. A review of recent research on mechanics of multifunctional composite materials and structures. Compos Struct 2010; 92: 2793-2810.

[2] Barone S, Cucinotta F, Sfravara F. A comparative Life Cycle Assessment of utility poles manufactured with different materials and dimensions. In: Advances on Mechanics, Design Engineering and Manufacturing. Springer International Publishing, 2017, pp. 91-99.

[3] Hinton MJ, Soden PD. Predicting failure in composite laminates: the background to the exercise. Compos Sci Technol 1998; 58: 1001-1010. 
[4] Liu PF, Zheng JY. Recent developments on damage modeling and finite element analysis for composite laminates: A review. Mater Des 2010; 31: 3825-3834.

[5] Babaei H, Mirzababaie Mostofi T. Modeling and prediction of fatigue life in composite materials by using singular value decomposition method. Proc Inst Mech Eng Part L J Mater Des Appl. Epub ahead of print July 2016. DOI: 10.1177/1464420716660875.

[6] Shivakumar K, Chen H, Abali F, et al. A total fatigue life model for model delaminated composite laminates. Int J Fatigue 2006; 28: 33-42.

[7] Gustin J, Joneson A, Mahinfalah M, et al. Low velocity impact of combination Kevlar/carbon fiber sandwich composites. Compos Struct 2005; 69: 396-406.

[8] Hassan MZ, Cantwell WJ. The influence of core properties on the perforation resistance of sandwich structures - An experimental study. Compos Part B Eng 2012; 43: 3231-3238.

[9] Atas C, Sevim C. On the impact response of sandwich composites with cores of balsa wood and PVC foam. Compos Struct 2010; 93: 40-48.

[10] Aktaş A, Aktaş M, Turan F. The effect of stacking sequence on the impact and post-impact behavior of woven/knit fabric glass/epoxy hybrid composites. Compos Struct 2013; 103: $119-135$.

[11] Sikarwar RS, Velmurugan R, Gupta NK. Influence of fiber orientation and thickness on the response of glass/epoxy composites subjected to impact loading. Compos Part B Eng 2014; 60: 627-636.

[12] Sutherland LS, Guedes Soares C. Impact on low fibre-volume, glass/polyester rectangular plates. Compos Struct 2005; 68: 13-22.

[13] Sutherland LS, Guedes Soares C. Effect of laminate thickness and of matrix resin on the impact of low fibre-volume, woven roving E-glass composites. Compos Sci Technol 2004; 64: $1691-1700$.

[14] Zhu S, Chai GB. Low-velocity impact response of composite sandwich panels. Proc Inst Mech Eng Part L J Mater Des Appl 2016; 230: 388-399. 
[15] Davies G a. O, Zhang X. Impact damage prediction in carbon composite structures. Int J Impact Eng 1995; 16: 149-170.

[16] Liu D. Characterization of Impact Properties and Damage Process of Glass/Epoxy Composite Laminates. J Compos Mater 2004; 38: 1425-1442.

[17] Belingardi G, Vadori R. Low velocity impact tests of laminate glass-fiber-epoxy matrix composite material plates. Int J Impact Eng 2002; 27: 213-229.

[18] Belingardi G, Vadori R. Influence of the laminate thickness in low velocity impact behavior of composite material plate. Compos Struct 2003; 61: 27-38.

[19] Belingardi G, Cavatorta MP, Salvatore Paolino D. Repeated impact response of hand lay-up and vacuum infusion thick glass reinforced laminates. Int J Impact Eng 2008; 35: 609-619.

[20] Belingardi G, Cavatorta MP, Paolino DS. On the rate of growth and extent of the steady damage accumulation phase in repeated impact tests. Compos Sci Technol 2009; 69: 16931698.

[21] Cucinotta F, Nigrelli V, Sfravara F. Numerical prediction of ventilated planing flat plates for the design of Air Cavity Ships. Int J Interact Des Manuf. Epub ahead of print 2017. DOI: 10.1007/978-3-319-45781-9_51.

[22] Cucinotta F, Nigrelli V, Sfravara F. A preliminary method for the numerical prediction of the behavior of air bubbles in the design of Air Cavity Ships. In: Advances on Mechanics, Design Engineering and Manufacturing. 2017, pp. 509-516.

[23] Cucinotta F, Guglielmino E, Risitano G, et al. Assessment of Damage Evolution in Sandwich Composite Material Subjected to Repeated Impacts by Means Optical Measurements. Procedia Struct Integr 2016; 2: 3660-3667.

[24] Bernardini F, Rushmeier H. The 3D Model Acquisition Pipeline. Comput Graph Forum 2002; 21: 149-172. 